\title{
Carburizing of steel
}

\author{
Jaleel Kareem Ahmad \\ College of Materials Engineering, Babylon University, Babylon, Iraq
}

\section{Email address:}

Jaleel_kareem@yahoo.com

\section{To cite this article:}

Jaleel Kareem Ahmad. Carburizing of Steel. International Journal of Materials Science and Applications. Special Issue: Steel and Direct Reduced Iron (Sponge Iron) Industry. Vol. 4, No. 2-1, 2015, pp. 11-14. doi: 10.11648/j.ijmsa.s.2015040201.13

\begin{abstract}
Paraffin wax (sulfur and phosphorous free)used as carburizer material for low carbon steels(Steel20, Steel3, and Steel 20x) instead of kerosene. Results show 1) Carburized layer by wax is more depth than in case of kerosene for all the three types of steel, e.g. for steel 20x the depths are 1.3360 .001 and $0.980 .15 \mathrm{~mm}$ respectively 2) More homogenized carburized layer by wax than by kerosene 3) Higher hardness carburized layer by wax than by kerosene, for steel $20 \mathrm{x}(61.5$ and 59.5 Rockwell Respectively) 4) Carburized layer by wax contains $0.017 \%$ sulfur and $0.98 \%$ carbon while $0.022 \%$ sulfur and 0.93 $\%$ carbon by kerosene 5) No sludge materials residue remain on the steel treated surface as in case of using kerosene 6) Under the same conditions (temperature, pressure, and volume) wax shows shorter time than kerosene to get the same depth of carburized layer 7) Wax is more save than kerosene as poisonous and fire hazard material 8) No corrosion effects on the furnace and its heaters in case of using wax than with kerosene (kerosene contains $0.2 \%$ sulfur).
\end{abstract}

Keywords: Carburizing, Kerosene, Paraffin Wax, Depth of Carburizing, Hardness

\section{Introduction}

Carburizing is the process of saturating the surface layer of steel with carbon. In accordance with carbon source, carburization is classified as [1,2]

1) Pack carburizing with solid carbonaceous mixtures (carburizer)

2) Gas carburizing and 3) liquid carburizing.

The main purpose of the carburizing process is to obtain a hard and wear resistance surface on machine parts by enrichment of the surface layer with carbon to a concentration from 0.75 to $1.2 \%$ and subsequent quenching. Steel which has been carburized and quenched (case hardened) has a higher fatigue limit. Low carbon steels, containing from 0.1 to $0.18 \%$ carbon, may be subjected to carburizing .Steel with a higher carbon content $(0.2$ to $0.3 \% \mathrm{c}$ ) may be employed for large components .Recently; there has been a tendency to use carburizing steel of higher carbon content for medium and small machine component as well. Steel with increased carbon content $(0.25$ to $0.35 \%)$ has a stronger core this enables the depth of the carburized case to be reduced thus simplifying subsequent heat treatment. In Russia [1] low carbon steel, grades 15, 20, and 25 , extensively used as carburizing steel. Alloy steels are used for highly stressed components, especially of large size, in applications when the core must posses' high mechanical properties and the case must be highly wear resistant. Such alloy steels include chromium steels (15x and 20x), chromium manganese- titanium steel (18xT and 30xT) chromium - nickel $(12 \times 2 \mathrm{H} 4 \mathrm{~A}$ and $12 \mathrm{XH} 3)$ and other .The use of alloy steels, as mentioned above, reduces distortion in quenching since oil used instead of water as a quenching medium. This enables complex machine parts to be successfully carburized and subsequently heat treated. Machine parts are carburized directly after machining or they may have an allowance of 0.05 to $0.1 \mathrm{~mm}$ for finish grinding. Selective carburizing is frequently applied. Carbon may diffuse into steel only if it is in the atomic state, i.e., as elemental carbon, for example, as the result of dissociation of carbon containing gases $(\mathrm{CO}, \mathrm{CH} 4$, etc.).Carburization comprises three consecutive stages:

1) Dissociation of the carbonaceous gases with the evolution of atomic carbon

$$
\begin{gathered}
2 \mathrm{CO} \underset{\text { or }}{\rightleftarrows} \mathrm{CO} 2+\underset{a t}{\longrightarrow} \\
\mathrm{CH} 4 \underset{\mathrm{H} 2}{\longrightarrow}+\mathrm{C}_{a t}
\end{gathered}
$$

2) Enrichment of the surface layer with carbon (the degree of saturation in this layer depends upon the carburizing temperature and the composition of the carburizer); and

3) Diffusion of carbon, adsorbed by surface, deep into the 
alloy. The diffusion rate depends on the carburizing temperature. The higher the temperature, the more rapidly carbon will be diffused.The structure of the carburized case may be described with the aid of the iron - carbon equilibrium diagram $[1,2]$

\section{Practical Part}

a) Requirement

1) Preparation of six samples of 3 types steel (st.20, st.3, st.20x) with diameter of $10-15 \mathrm{~mm}$ and $30 \mathrm{~mm}$ length. Their chemical compositions are determined using Xray fluorescence is listed in Table 1.

Table 1. Chemical composition of steel samples.

\begin{tabular}{lllllll}
\hline Steel type Dimension $(\mathbf{m m})$ & $\mathbf{C} \%$ & Si\% & Mn\% & Cr\% & Fe\% \\
\hline St.20 & $30 \times 10$ & 0.19 & 0.17 & 0.50 & 0.100 & Rem. \\
St. 3 & $12 \times 30$ & 0.14 & 0.20 & 0.35 & 0.100 & Rem. \\
St.20x & $15 \times 30$ & 0.23 & 0.29 & 0.64 & 0.78 & Rem. \\
\hline
\end{tabular}

2) Carburizing Furnace

Carburizing furnace model 4-60, Russian made is used (Table 2.). This type of furnace suitable for carburization by gas. It is a perpendicular furnaces provided with a fan to homogenize the furnace atmosphere and make a positive pressure as well as there are two orifices in its cover, one links by a pipe to the dropper system, while the other for exhausted gases which are used as fuel (contains carbon monoxide gas) to heating the carburizer (wax) beside the heat from the hot furnace cover in which the aluminum wax tank touch it directly

Table 2. Furnace Specifications

\begin{tabular}{ll}
\hline Power & $60 \mathrm{~kW}$ \\
Frequency & $50 \mathrm{~Hz}$ \\
Voltage & $380 \mathrm{~V}, 3$ Phases \\
Max. Temperature & $950 \mathrm{C}$ \\
Empty furnace power & $15 \mathrm{~kW}$ \\
Furnace charge & $150 \mathrm{~kg}$ \\
Inner dimension & $450 \mathrm{~mm}$, depth $600 \mathrm{~mm}$ \\
\hline
\end{tabular}

\section{b) Carburization method}

Experiment starting by putting the steel samples inside the furnace then the furnace switch on until the temperature reaches $850 \mathrm{C}$ then the dropper system starts with a rate of 60 drops / min of the melting wax $(\sim 130 \mathrm{C})$, heating of the furnace continues up to $930 \mathrm{C}$ within two hours, then the dropping rate increases to 120 drops / $\mathrm{min}$ for six hours after that the furnace switch off and the samples left overnight inside the furnace .Nearly two liters of liquid paraffin is consumed during the whole experiment. For comparison and under the same conditions the experiment is repeated with white kerosene which is already used in the State Company for Mechanical Industries / Ministry of Industry and Minerals / Iraq, according to Russian technology.

Specifications of both kerosene and wax are listed in Tables 3 and 4 [3]

Table 3. Specification of kerosene

\begin{tabular}{ll}
\hline Specific gravity at $15.6 \mathrm{C}(\max )$ & 0.801 \\
Flash point (Abel) C(min) & 38 \\
Distillation at $185 \mathrm{C} \%(\min )$ & 20 \\
Final boiling point C(max) & 300 \\
Color (saybolt) (min) & +16 \\
Sulfur content \%w (max) & 0.2 \\
Doctor test & Negative \\
Odour & Acceptable \\
Char value $\mathrm{mg} / \mathrm{kg}(\max )$ & 20 \\
Smoke point $\mathrm{mm}(\min )$ & 25 \\
Aromatic content \% v (max) & 20 \\
Calorific value kcal / kg (gross) Est. & 10900 \\
\hline
\end{tabular}

Table 4. Specification of wax

\begin{tabular}{ll}
\hline Penetration at $25 \mathrm{C}$ & 34 \\
Oil content wt \% (max) & 1.5 \\
Melting point C & 48 \\
Color (saybolt) (min) & +20 \\
Sulfur & Nil \\
\hline
\end{tabular}

c) Test and chemical analysis

Each carburized steel sample (st.20, st.3, st.20x) cuts in two parts then hardening the two parts in a box electric furnace at $80010 \mathrm{C}$, then tempering at $200 \mathrm{C}$ for one hour. Hardness test is carried on one part and the microstructure test on the other part. The other sample sends for carbon and sulfur chemical analysis without hardening to simplify the process of taking powder sample for chemical analysis. These processes are also carried on for those which are carburized by kerosene. Table 5 shows the results of the hardness test.

Table 5. Shows the values of the hardness after hardening and tempering.

\begin{tabular}{llll}
\hline Sample & Diameter of sample (mm) & Hardness by wax ( HRC) & Hardness by kerosene (HRC) \\
\hline St. 20 & 11 & $60-61$ & $50-54$ \\
St. 3 & 12 & $56-60$ & $45-50$ \\
St. $20 \mathrm{x}$ & 15 & $59-64$ & $59-60$ \\
\hline
\end{tabular}

Chemical analysis

Carbon and sulfur are determined by combustion method followed by absorption. The results are listed in Table 6 .

Table 6. Percent of elemental carbon and sulfur.

\begin{tabular}{lll}
\hline Carburized sample & $\mathbf{C \%}$ & S\% \\
\hline By wax & 0.98 & 0.017 \\
By white kerosene & 0.93 & 0.022 \\
\hline
\end{tabular}


Table 7. Depth average values for carburized layers

\begin{tabular}{lll}
\hline Sample & Depth average value by wax $(\mathbf{m m})$ & Depth average value by kerosene $(\mathbf{m m})$ \\
\hline St. 20 & $1.372 \pm 0.033$ & $1.2675 \pm 0.074$ \\
St. 3 & $1.24 \pm 0.0048$ & $1.0075 \pm 0.14$ \\
St. $20 \mathrm{x}$ & $1.336 \pm 0.001$ & $0.98 \pm 0.15$ \\
\hline
\end{tabular}

\section{Depth of carburized layer}

This test carried out microscopically after polishing then etching the samples by nital solution $(2 \%$ nitric acid in alcohol). The values are listed in Table 7.

Diffusion test for carburized steel by wax

Carbon deposited test shows carbon gradually distributed from the outer steel surface to the alloy core as continuous film and this is clear from the gradual appearance of ferrite structure as shown in photo (4-6)

Microscopic test for carburized layer by kerosene

Test shows principal structure for all carburized steel samples are martensite only with low percent carbides (photos 7-9) comparing with carburized steel samples by wax (photos 1-3).

This indicates that the carbon deposits from wax higher than that from kerosene[4] and this causes the extra appearance of carbides in the carburized steel samples by wax which agree with the values in Table 6 .

Carbon diffusion test for carburized steel samples by kerosene

Test shows that carbon diffusion not gradually occurs (photos 10-12). The ferrite structure appears more accumulated on the carburized layer boarder line and this is undesirable state in the heat treatment field

Note: All photos with magnification of $400 x$

\section{Results and Discussion}

Microscopic test for the carburized layer by wax shows martensite structure containing fine carbides homogenously distributed ( photos 1-3 ) as well as we noted an slightly increment in carbides in the formed layer in the st.20x ( photo3), this is due to the fact that this steel contains relatively high percent chromium (Table 1) which enhances carbide formation[5,6]. Results show clearly that wax more better than white kerosene as carburizer for steel, this

is due to the fact that the depth of carburized layer by wax higher than that by kerosene as well as more homogenous and there is no gap between the diffused carbon layer and alloy core (photos 4-6)

In case of white kerosene the principal structure for all carburized samples is martensite with a presence of low carbides percent (photos 7-9) comparing with wax carburized samples (photos 1-3) which agree with Table 4 that carbon deposits from wax higher than that from kerosene result in more carbide formation by wax as well as sulfur inhibits carbide formation[6] (Table 3).

Diffusion tests for the carbon layer by kerosene shows that carbon diffusion not take place gradually (photos 10-12) and ferrite structure appears in more quantity on the carburized layer boarder line which is undesirable state in the field of heat treatment processes, while in case of wax carbon diffuses gradually from the outer surface towards the core of the sample and test doesn't show discontinuity between the carbon layer and the center of the sample and this is clear from the gradually appearance of the ferrite structure as shown in photos (4-6).

Hardness for carburized samples by wax show higher values than that by kerosene (Table 5) may be that carbon deposits from wax higher than that from kerosene (Table 6), wax has higher carbon potential than kerosene [7]. More carbon percent more chance for carbides formation thus higher hardness, also kerosene has $0.2 \%$ sulfur [3] while wax is sulfur- free. Sulfur has bad effect on the mechanical properties of steel and acts as inhibitor for carbide formation as well as attack furnace heaters.

Wax leaves the carburized samples very clean, thus no cleaning step required as in case of kerosene in which the samples left with sludge residue. This is due to the impurities and to the vigorous deposition of carbon from kerosene [7, 8]. Under the same condition of temperature, pressure, volume and time, wax seems more efficient to provide a carbon layer deeper than that by white kerosene, this result in reduction of $\sim 10 \%$ for the same depth

of the formed carbon layer i.e. by wax there is a saving in electrical energy by $10 \%$. This explain by the fact that wax molecule has a chain length nearly double than that for white kerosene molecule, thus wax molecule undergo a cracking phenomena i.e. transform into shorter chain molecules follow by partially oxidized to carbon monoxide ,carbon dioxide and water vapor, then decomposition into elemental carbon as follow [7,9]

Short carbon chain molecule $\underset{\text { Presure }}{\longrightarrow}$ Long carbon chain wax molecule $+\mathrm{O} 2 \rightarrow \mathrm{CO}+\mathrm{CO} 2+\mathrm{H} 2 \mathrm{O}$

Short carbon chain molecule $2 \mathrm{CO} \rightleftarrows \mathrm{CO} 2+\underset{a t}{C}$ diffusion (atoms on the steel surface)

Thus wax molecule feeds steel samples with carbon homogenously and continuously which enhances diffusion and carburization processes. This is not take place in case of relatively short kerosene molecule result in fastly accumulated carbon on the samples as well as sludge formed from the impurities contest in it which inhibits the above two processes.

Also wax molecule consumes oxygen by combustion process nearly twice than that with kerosene molecule result in oxygen deficient in the furnace atmosphere in case of wax more than in case of kerosene which decreases the probability of carbon dioxide formation. Both gases (oxygen and carbon dioxide) oxidize the steel and inhibit carburization process. 


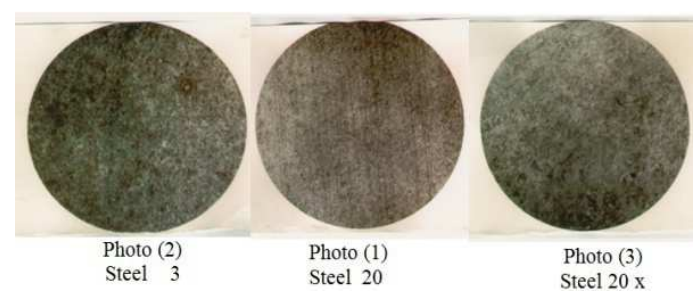

Photos show microstructure of carbonized layer by wax

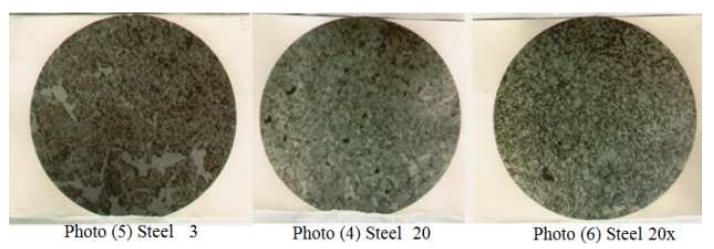

Photos show diffusion of carbon by wax from the surface to the steel core

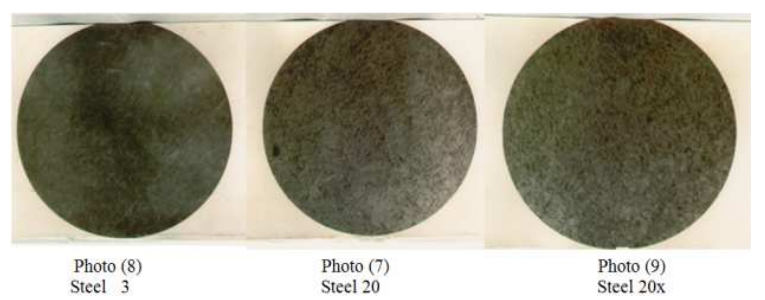

Photos show microstructure of carbonized layer by kerosene

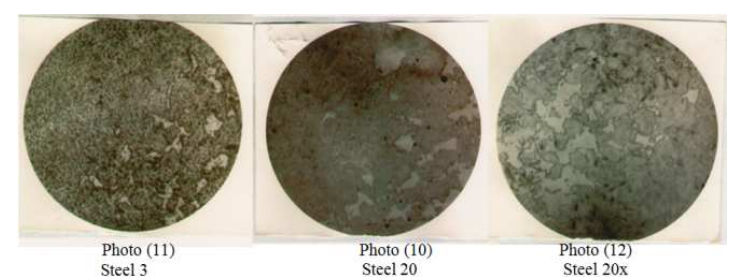

Photos show diffusion of carbon by kerosene from the surface to the steel core

\section{Conclusion}

Results shows that wax is better carburizing agent than kerosene due to the fact that wax molecule has higher carbon potential than kerosene molecule thus result shows wax carbon layer deeper than that of kerosene as well as mechanical properties with wax better than with kerosene due to the presence of sulfur and phosphorous compounds in kerosene which have bad effects on the mechanical properties of the product steel.

\section{References}

[1] Y. Lakhtin, Engineering Physical Metallurgy MIR publishers,Mosco (1977)

[2] Darken and Gurry, Physical Chemistry of Metals from the Sieres of Metallurgy and Metallurgical Engineering, Mc Graw - Hill Book company (1953)

[3] Marketing Specifications of Iraqi Petroleum Products , Ministry of Oil , Iraq ( 2000)

[4] Yannick Vallee, Gordon, and Breach ( Editers), Gas phase Reactions in organic Synthesis, Science Publishers (2002)

[5] Ahmad Moosa, Jalil K. Ahmad, and Ali Hoobi , Chinese Journal of Aeronautics 20 ( 2007)

[6] Ahmad Moosa , Jalil K. Ahmad , and Ali Hoobi , Material Science Forum Vols . 546-549 (2007)

[7] Philip L. Walker, JR . and Peter A. Thrower ( Editers ), Chemistry and Physics of carbon, Series of Advances Vol. 15, Marcel Dekker, INC ( 1965)

[8] A.William Johnson , Invitation to Organic Chemistry, Jones and Bartlett Puplishers (1999)

[9] Jaleel K. Ahmad, J. Adv . Oxid . Technol . Vol .13, No.1, (2010) 